\title{
Speaking and Writing Connections in L2: \\ The Roles of Multimodal Teaching and Learning \\ Joohoon $\mathrm{Kang}^{\dagger}$ \\ Sangmyung University
}

\begin{abstract}
This study aims to review speaking and writing connections in L2 and discusses how multimodality is related to speaking and writing connections. The paper opens with a brief history of speaking and writing connections in the fields of both L1 and L2. Next, some major theoretical approaches related to speaking and writing connections are discussed. Following that, the major literature in the area is presented and discussed with a primary focus on L2 research. Additionally, the influence of speaking and writing modalities on each other, is presented by discussing writing-to-speak and speaking-to-write. Next, multimodal movement and the relationships between multimodality and speaking and writing connections are discussed. This study also investigates how multimodality is applied in speaking and writing connections scholarship. Finally, the future direction and pedagogical implications are provided.
\end{abstract}

Keywords: speaking and writing connections, L2 teaching and learning, multimodality

\section{Introduction}

It has taken some time for connections between reading and writing to receive the attention they deserve in second language (L2) teaching and learning. At present, it is widely accepted that one cannot successfully teach/learn writing without simultaneously teaching/learning reading (Hirvela, 2004). L1 scholars have supported connecting speaking and writing for more than three decades (see Kroll \& Vann, 1981; see also Horowitz, 2007). On the other hand, speaking and writing connections have been relatively neglected in the L2 field, despite emerging interest in the field (Hirvela \& Belcher, 2016).

There seem some plausible reasons for such indifference to this topic in the L2 field. Belcher \& Hirvela (2008) explained that L2 writing professionals (e.g., Zamel, 1982) deliberately attempted to separate writing from speaking in order to authorize

\footnotetext{
${ }^{\dagger}$ Corresponding author: joohoonkang@gmail.com
} 
writing as a legitimate object of literacy study, "more than a pale reflection and means of reinforcement of spoken discourse" (p. 1). L2 writing scholars have also tended to present writing as a means to discover meaning, express oneself, and transform knowledge (Zamel, 1982). This may have led to the failure to pay proper attention to oral or spoken discourse in L2 writing. Another factor may be the popularity of Communicative Language Teaching (CLT) that has prevailed since the 1980s (Hirvela \& Belcher, 2016). Although CLT attempts to combine all four linguistic skills (i.e., reading, listening, writing, and speaking), speaking is viewed as the primary skill for communicative competence from the CLT perspective (see Savignon, 1983): CLT might fail to recognize writing as important as speaking. L2 writing scholars and CLT proponents have ascribed different values to each skill in particular, to speaking and writing, which may have contributed to distracting their attention from speaking and writing connections (Hirvela \& Belcher, 2016).

However, some L2 professionals started to take note of a seemingly implicit and/or indirect relationship between speaking and writing, even though speaking and writing connections were not the main focus of their studies (Belcher \& Hirvela, 2008; Hirvela \& Belcher, 2016). In particular, many attempts have been made to explore oral activities in the L2 writing classrooms, such as group pre-writing activities, peer responding, teacher conferencing, and writing center tutorials (see Weissberg, 2006).

It might be necessary to inquire into the reasons why speaking and writing should be connected. Is there any benefit of connecting speaking and writing, which appear to be mutually at odds with each other? Speaking and writing, in fact, are not contradictory, but complementary as both are communicative output skills (Hyland, 2016). Oral discourse plays a significant role in learning to write, and written discourse also could have a beneficial impact on speaking (Kantor \& Rubin, 1981). Thus, it seems essential to investigate and understand the nature of their relationship, which will be, after all, advantageous for L2 learners' literacy development and their oral proficiency.

In addition to the complementary property of speaking and writing, speaking and writing connections seem to be interesting with a growing recognition of the significance of L2 learners' multimodal literacy practices (e.g., digital storytelling). As L2 learners engage in multimodal literacy practices, they would increase their diverse language skills across multiple forms, including linguistic features (e.g., written and oral resources). That is, L2 learners would have a chance to improve their writing skills through several revisions of their scripts. Simultaneously, they 
would increase their speaking skills while attempting to produce their best work through repetitive autonomous practice. The development of integrated linguistic skills (e.g., speaking and writing connections) could be encouraged through multimodal literacy practices.

To introduce multimodal turn in speaking and writing connections, this study starts with a brief history of speaking and writing connections in the fields of both L1 and L2. Next, some major theoretical approaches related to speaking and writing connections are discussed. Then, the major literature in the area with a primary focus on the L2 literature is presented. Also, this study discusses how the two modalities, speaking and writing, influence each other, by discussing writing-to-speak and speaking-to-write. Next, it presents a multimodal turn and discusses how multimodality is applied in speaking and writing connections scholarship. Finally, some future directions and/or implications are provided.

\section{Brief History}

\subsection{Speaking and writing connections in L1}

Not only in the L2 field, but also in the L1 field, not many studies have directly explored speaking and writing connections. It was assumed that learners would acquire oral language skills much earlier than written language skills. Also, some L1 scholars assumed that writing might be the mere outcome of speaking, and thus writing development might be highly reliant on speaking improvement (see Kroll \& Vann, 1981). Thus, written discourse, as just speech-written-down, was not considered a valuable object of attention or study in the L1 field (Schafer, 1981). In contrast, a spoken discourse has long been viewed as a primary mode of communication more so than written discourse, which hence had not been "considered worthy of serious attention" (Schafer, 1981, p. 2). Therefore, many L1 scholars believed that they should view spoken language as the idealized object and data of the study, suitable for describing a language system (e.g., part of speech). Instead, written discourse was considered expressed speech, which might be one of the seemingly accessory language events (see Schafer, 1981).

However, in the early 1960s, some L1 scholars of the National Council of Teachers of English (NCTE) in the US began to challenge this assumption about written and oral discourses (Kroll \& Vann, 1981). Since then, more and more 
scholars from diverse disciplines have joined the investigation into the relationship between speaking and writing. One such work is Kroll's (1981) study on the relationship between children's written and oral language skills. He proposed a developmental model with the purpose of enlightening children's speaking- and writing progress. The model consists of four continuing phases of development: preparation, consolidation, differentiation, and systematic integration (Kroll, 1981).

The first phase of the model is preparation, in which children would learn basic technical skills about how to represent their speech in written symbols. Their writing skills are considered limited, and speaking and writing are known to be separate in this phase. In the next phase, consolidation, children's writing would become heavily dependent on their oral speech. Here, speaking and writing are known to begin getting integrated, and writing seems like "talk written down" (p. 39). Then, it is noteworthy that children begin to learn the different styles and structures of each modality in the third phase, differentiation. In the last phase, integration, their writing and speaking are "both appropriately differentiated and systematically integrated" (p. 39). It is at this stage that the learners' speaking and writing skills might each serve a different purpose, audience, and context.

Some other L1 scholars have explored the differentiation stage more thoroughly and deeply to further clarify speaking and writing connections. For instance, Kantor and Rubin (1981; see also Rubin \& Kantor, 1984) proposed a model of inter-related development about spoken and written discourses. They argued that speech would not be a precursor to writing, since the development of oral discourse would continue after the onset of writing. Instead, speaking and writing would progress simultaneously (see Kantor \& Rubin, 1981 for more details). Also, Kantor and Rubin (1981) claimed that growth in speaking can influence development in writing, and vice versa. Based on their conclusion, it is possible to consider speaking and writing to have a reciprocal and bidirectional influence.

\subsection{Speaking and writing connections in L2}

A small but growing body of scholars began to examine L2 learners' related learning processes of speaking and writing. One of the main issues is whether L2 learners' developmental progress of speaking and writing would be similar to or different from that of L1 learners. If they are different, how and to what extent they are different needs to be addressed. Some scholars support the idea that the L2 (writing) developmental process would be the same as that of L1 (e.g., Roebuck, 
2000). However, there appears to be a general consensus among L2 professionals that L2 learners would go through more complicated processes than the L1 acquisition's process (Weissberg, 2006).

Since the 1970s, L2 literacy scholars have investigated the role of oral language in learning to write. For example, Dickinson, Wolf, and Stotsky (1993) compared L1 and L2 children's learning processes, and found that both groups showed a similar pattern: their early writing was heavily dependent on oral language, as in Kroll's (1981) developmental model. The findings of the study showed that children frequently used the first- and second-person pronouns in their writing, as they did when speaking. Children also were reported to overuse the same words, active voice, present tense, and coordinating conjunctions (e.g., and) just as they did when engaging in oral discourse. However, the authors also noted that L2 children's later writing development differed from individual to individual, unlike their early writing development (Dickinson et al., 1993). Even though most children attained the mastery of their oral L1, they showed much more variation in the levels of their writing skills, which proves that each L2 learner's writing development was significantly different, particularly at their later ages.

Furthermore, Weissberg (2006) proposed that the relationship of L2 learners' individual writing development to speech would vary more widely. Of course, some L2 learners would follow the same pattern of the developmental model of L1 learners, such as some L2 learners who immigrated to English-speaking countries at an early age, and those, called Generation 1.5, who were born in English-speaking countries, but exposed to other languages than English in their homes, as noted in Harklau's (2002) study. For them, spoken language would be critical to developing their writing skills. However, most adult learners do not learn L2 the same way as they learn their L1 (Lightbown \& Spada, 2013). One of the significant differences between L1 and L2 learning is that adult learners' L2 learning might be prompted more by engaging in L2 writing activities (e.g., brainstorming or self-revision) than through engaging in L2 oral interactions (Weissberg, 2000). Many adult L2 learners do not rely on their L2 speaking competence as a foundation for their L2 writing development. For example, some international students at U.S. universities would begin to develop their written English in the near absence of L2 oral skills (Harklau, 2002).

However, some L2 scholars tend to maintain that literacy skills are subordinate to speaking development. L2 oral proficiency has been assumed to be a critical factor for L2 writing development (e.g., Cumming, 1989). Yet, this linear relationship 
between speaking and writing might be not so clear, especially for L2 learners. As speaking affects writing development, writing could affect speaking development, even if it seems less obvious (Williams, 2008). Therefore, it is timely to further investigate the relationship between the speaking and the writing of L2 learners to understand the connections between these two modalities (i.e., speaking and writing).

\section{Theoretical Approaches}

Before presenting the findings of the research on speaking and writing connections, some related theoretical approaches are discussed to understand what makes speaking and writing connections more theoretically convincing in the L2 field.

\subsection{The sociocultural approach}

With the social turn, the work of Vygotskian sociocultural theory (SCT) has provided theoretical rationales for integrated skills that include speaking and writing, and collaborative activities (Lantolf, 2000). According to the SCT perspective, speech is a fundamental element for facilitating learners' - especially of children's - writing skills. Learners are known to, at first, constitute inner speech, an initial basis for writing through social interactions with others, especially experts. Inner speech, thus, is referred to as a silent, mediated, and internalized social talk (Vygotsky, 1986). Then, learners are encouraged to express inner speech as a form of writing, which is viewed as 'externalized' inner speech (Wertsch, 1991). As such, most advocates of SCT argue that speaking always precedes writing, in alignment with L1 scholars' view on language development.

Another significant concept of SCT, which contributes to speaking and writing connections, is the zone of proximal development (ZPD), which refers to the learning distance between what learners can do on their own and what they can do with assistance from others (e.g., experts) (see Lantolf, 2000). Thus, the ZPD concept asserts that scaffolding between an expert and a novice is central to the learning process. This view provides strong support for collaborative learning in the L2 writing class. Social interactions (e.g., conversation) between the teacher and students as well as among peers play a crucial role in developing learners' writing 
skills. This role of social interactions stressed in sociocultural theory transforms the L2 writing class from one that is teacher-centered, to one that is more socialized and interactive (Lantolf, 2000). Based on this trend, many collaborative classroom activities, including oral interactions, have been introduced in the L2 writing classroom (e.g., responding to students' writing) (see Weissberg, 2006).

Owing to sociocultural theory, social interactions have received proper attention in both research and in the L2 writing classroom. Therefore, SCT has provided strong support for speaking and writing connections. However, SCT cannot entirely escape from being criticized. Most criticism has been directed at the assumption of SCT that the ability to write follows oral development, and L1 and L2 are developmentally equivalent (see Weissberg, 2006, 2008). Other scholars make a different assumption, that speech might not be the requisite precursor for L2 learners' writing development. Weissberg (2000) found that some L2 learners could develop their L2 writing and speaking skills independently, and further, for some L2 learners, skills/knowledge gained from social interactions might not directly transfer to literacy skills (through inner speech). As discussed above, some L2 learners, such as international college students, develop their writing skills without corresponding speaking skills. Accordingly, SCT might not hold status as a universal model because it might not necessarily be compatible with L2 writing development. Even so, SCT still has significant value for L2 pedagogy, which supports diverse collaborative practices in the L2 writing classroom.

\subsection{The dialogic approach}

Rather than indiscriminately adopting SCT, Weissberg (2008) argued for a modified or extended version of SCT, which is Bakhtin's dialogic approach. Bakhtin viewed spoken and written discourses as "interactive or, in a broader sense, dialogic processes" (Marchenkova, 2008, p. 49). Dialogue seems to include both speaking and writing communication. The main difference between SCT's inner speech and Bakhtin's dialogue is that the latter does not necessarily result from external social talks as the former does. Bakhtin (1986) suggested that dialogue is realized or internalized through involvement in various human activities, which do not need to take place outside. That is, from the dialogic approach, L2 learners can internalize their dialogue, and hence develop their writing skills by employing various resources, not only from outside, but also within themselves (Wong, 2006). Thus, the dialogic approach encourages L2 learners to take advantage of many different opportunities 
to develop their own internal dialogues through self- referencing resources (e.g., journals or their own previous writing assignments) (Peyton \& Reed, 1990), as well as collaborative talk-write activities (e.g., peer and group work).

Another assumption of Bakhtin's dialogic approach is that L2 learners, with the development of their writing skills, can develop their own voice, which can be referred to as identity, through the process of internalizing dialogue (Marchenkova, 2008). Bakhtin (1986) suggested that dialogue becomes meaningful only through the use of voice, identity, or authorship. That is to say, speakers' overall perspective or world value can be manifested through their voice (Wertsch, 1991).

Vygotskian SCT sheds light on speaking and writing connections of L1 speakers and some L2 writers, who are exposed to L2 at an early age: SCT can be employed as a theoretical framework to address their speaking and writing connections. However, one should guard against blindly adopting SCT, especially when addressing L2 adult learners' speaking and writing connections (Weissberg, 2008). Instead, Bakhtin's theory of dialogue appears a more appropriate conceptual basis for L2 learners' speaking and writing development.

\subsection{The multimodality approach}

One of the reasons for combining multiple modalities for meaning-making and communication might be the recent advance of technologies. Consequently, people are increasingly encouraged to engage in hybrid forms of communication (e.g., online chatting, blogging, and digital storytelling), which include multiple semiotic modes (e.g., visual, aural, spatial, and gestural resources) (Kress \& van Leeuwen, 2001). These hybrid forms also include different linguistic modalities, such as speaking and writing. As learners engage increasingly in multimodal activities, combined linguistic modalities (e.g., speaking and writing connections) tend to receive more attention in the field.

Multimodality approach "is an interdisciplinary, social semiotic approach that understands communication and representation as the integration of modes for meaning-making" (Yi \& Angay-Crowder, 2016, p. 990). Multimodal researchers have thus been interested in exploring how meaning is constructed through multiple semiotic modes. In this regard, multimodality is likely to be viewed as a valuable theoretical approach for framing research on connections between speaking and writing (Hirvela \& Belcher, 2016; van Leeuwen, 2015). More information about how multimodality is related to speaking and writing connections will be discussed later 
in this paper.

\section{Research on Speaking and Writing Connections}

In this section, the major literature on speaking and writing connections with a primary focus on L2 is discussed. Hirvela \& Belcher (2016) have categorized studies relevant to the topic along three themes: (1) writing-focused (speaking to write), (2) speaking-focused (writing to speak), and (3) multimodal-oriented. Herein, this categorization of the themes has been adopted to discuss the related literature. At the same time, the literature reviewed within each category does not necessarily belong exclusively in that category.

\subsection{Speaking to write}

It is widely accepted in both L1 and L2 fields that speaking affects writing in many ways. In fact, most studies relevant to speaking and writing connections have explored ways in which speaking scaffolds writing, providing support for speaking as a means of improving writing (Williams, 2008). Also, most of the evidence provided by studies relevant to speaking-to-write stem from the sociocultural perspective, which suggests that knowledge is mediated by inner speech through social (external) interactions with others (e.g., peers and experts) (Lantolf, 2000). That evidence is categorized into three areas of research: (1) teacher-student conferences, (2) peer responses, and (3) writing tutorials.

\subsubsection{Teacher-student conferences}

Patthey-Chavez \& Ferris (1997) examined teacher-student conferences, drawing upon the zone of proximal development (Vygotsky, 1986). The authors investigated improvements (or lack thereof) in students' drafts as a result of conferencing with teachers. The authors collected a total of 32 drafts from 8 students, tape-recorded student-teacher conferences, and analyzed them using both qualitative and quantitative analyses. They found that all participants actually revised their drafts despite slight differences in their revisions based on their different language proficiency and cultural backgrounds from one another. With the aid of teachers, all students' papers were more within the acceptable range of "academic discourse" 
(p. 83). Patthey-Chavez \& Ferris's (1997) findings indicate that students' engagement in oral interactions with their teachers might have indirectly and positively influenced them to be more confident in revising their drafts. Yet, the researchers also pointed out that a possible disadvantage of teacher-student conferences is that less competent students would be more likely to follow their teachers' suggestions uncritically, rather than actively negotiating with their teachers during the conferences.

Another example is found in Ewert's (2009) study, which mainly investigated two teachers' discursive features during their writing conferences with L2 learners. Ewert (2009) intended to see what would contribute to L2 learners' participation in interactions and the subsequent revision of their drafts. The author reported that some combinations of negotiation and scaffolding would encourage students to engage in oral interaction with teachers. Ewert (2009) also found that a focus on the content and rhetorical issues around fewer topics during conferences would promote students' participation, and thus lead to their "successful revisions and learning" (p. 268).

\subsubsection{Feedback in peer response groups}

Many L2 professionals have recognized that peer feedback and writing workshops can provide scaffolding for L2 learners to perform tasks beyond their own capacity, and can enable them to revise their drafts effectively (Hyland, 2008). Students who engage in peer feedback are usually asked to focus on the content and rhetorical aspects of writing, rather than on linguistic or grammatical features (Liu \& Hansen, 2002). However, peers are still more likely to pay attention to the micro-aspects (e.g., typo), rather than the content (i.e., the meaning, thesis, support, or argument), of their writing. Nonetheless, any form of oral interaction with peers during the writing process has been found to be beneficial for L2 learners' writing skills (Weissberg, 2006).

More particular evidence for peer interactions is found in Yang's (2008) study, which reported that peer-peer dialogues in both oral and written forms were useful for L2 learners' writing development (e.g., improved group papers). The author found that L2 learners could have a better understanding of the subject matters and instructors' requirements through peer talks. Furthermore, Yang (2008) showed that peer-peer dialogue can facilitate L2 writers' proper use of language, idea development, and then revision of their drafts. It is important to recognize the fact that an 
improved revision may result from unfavorable (e.g., rejection, criticism, or resistance), as well as friendly and constructive feedback in conversations with peers (Yang, 2008). This finding provides strong support for speaking-writing connections in the L2 composition classroom.

Similarly, Hyland (2008) also presented evidence for speaking-to-write. She explored the nature and role of peer conversations in two different writing workshops. In her study, two teachers organized and managed their own writing groups differently from one another. One teacher focused on academic writing and individual problem solving, while the other focused on the writing process and peer interactions. Despite having different organizations and management, both groups showed that oral interactions with peers would be the starting point for students to develop and refine their ideas. Further, Hyland (2008) found that "oral discussion is a way of confirming and elaborating their understanding of the writing task itself, as well as being of practical assistance" (p. 187). The author frequently observed informal peer interactions in both groups, which students recognized as being important to them. Thus, the study called for further research, which will attempt to explore L2 learners' informal peer interactions, especially in the out-of-school context, where they would have more autonomy and control over how to use various resources to facilitate their writing development.

\subsubsection{Writing center tutorials}

Speaking-to-write is also exercised in L2 learners' oral interactions with writing center tutors, who are more proficient interlocutors. Writing center tutors are considered experts, and L2 learners, novices. From the sociocultural perspective, scaffolding between tutors and students is critical for developing L2 speaking and writing (Williams, 2008). For example, Williams (2004) explored how writing center tutors affect the revisions students make. Williams's findings demonstrated that L2 learners usually made sentence-level changes in their subsequent drafts after engaging in oral interactions with writing center tutors. The author also found that students were more likely to revise their drafts when they more actively participated in conversations with their tutors and when their tutors made explicit suggestions.

In another study of the effectiveness of writing center tutorials, Thonus (2004) compared the interactions of writing center tutors with native speaker (NS) tutees versus with non-native speaker (NNS) tutees (L2 learners). The author noticed significant differences between them; the writing center tutors tended to dominate 
conversations when they interacted with NNS tutees, and not when they interacted with NS tutees. Thonus (2004) also found that NNS tutees spoke less in interactions with their tutors than did NS tutees. The author, therefore, recommended that writing center tutors need to understand the various reasons why NNS tutees feel frustrated and are unwilling to join oral interactions, so that they can provide NNS tutees with better learning opportunities to develop their speaking and writing skills.

\subsection{Writing to speak}

Most L2 research relevant to speaking and writing connections has focused on one direction, from speaking to writing; thus, only a few studies have explored how writing scaffolds speaking. One reason for this widespread perception of a unidirectional relationship between these modalities is that it is generally accepted that people develop their writing skills after they acquire their L1 oral competence, and L2 professionals may be following this trend (Nelson \& Lu, 2008; Williams, 2008). In fact, many L2 scholars, influenced by the sociocultural perspective, maintain that writing skills emerge from inner speech, or a speaking-mediated activity through oral interactions with others, and they overlook the possibility that writing also scaffolds speaking. (Weissberg, 2008). The problem is, as Weissberg (2006, 2008) indicated, that L2 development is not necessarily compatible with L1 development. Also, some other scholars have observed that L2 learners' writing skills could play a significant role in their speaking development, and thus writing could also scaffold speaking in different ways (see Rubin \& Kang, 2008). This overall unbalanced view of the relationship between speaking and writing needs to be redressed.

A growing body of research in the fields of both L1 and L2 suggests that speech and writing seem to be reciprocally dependent (e.g., Kantor \& Rubin, 1981, Rubin \& Kantor, 1984; Rubin \& Kang, 2008). However, as Williams (2008) has pointed out, ways in which writing scaffolds speaking appears to be indirect and rather implicit, while it is more clearly and explicitly accepted that speaking affects writing development. Therefore, further investigation is needed to identify more direct roles of writing in speaking development, thereby providing a better understanding of the bidirectional nature of speaking and writing connections. In the following sections, I discuss the role of writing in speaking development in terms of (1) increasing meta-knowledge awareness, (2) guiding oral performances \& interactions, and (3) contributing to oral linguistic competence. 
On the outset, it appears sensible to say that "it is not possible to propose any direct influence of writing on the development of L2 competence that underlies oral proficiency" (Williams, 2008, p. 12). However, it is still practically and theoretically essential to investigate both implicit and (if any) explicit roles of writing in oral performance and development. And writing is assumed to have an influence on meta-knowledge of speaking.

First of all, "acquiring the print code affects 'metalinguistic' representation of speech" (Rubin \& Kang, 2008, p. 214). Metalinguistic awareness, also known as metalinguistic ability, refers to the learners' ability to recognize language as an object (Olson, 2002). Simply put, metalinguistic awareness is the ability to know about language. The more people have metalinguistic awareness, the more they visualize language and understand segmental constituent units of speech (e.g., phonemic boundaries) (Tarone, Bigelow \& Hansen, 2009). Thus, learning to encode and decode alphabetic scripts (i.e., reading and writing) could affect ways in which one produces his/her own speech (e.g., pronunciation), as well as how to listen to others' speech, in accordance with the print code (writing system) (Olson, 2002). Thus, writing could affect speaking in so far as it augments the metalinguistic awareness of speech (Rubin \& Kang, 2008).

Second, "developing written discourse affects 'metarhetorical' awareness of oral structures" (Rubin \& Kang, 2008, p. 215). Written discourse received little attention from scholars, particularly rhetoricians, because they viewed writing as just speech-written-down (see Kroll, 1981). However, as other scholars argue, writing is not just a reflection of speech, but a valuable object of inquiry (Kantor \& Rubin, 1981). Thus, after the advent of the writing system (e.g., alphabet), many rhetoricians started to explore spoken discourse "by extrapolating from writing" (Rubin \& Kang, 2008, p. 215). Also, scholars in the fields of both L1 and L2 are increasingly interested in the distinct properties of writing, such as slower pace, which could contribute to appreciating the rhetorical structures of speaking as well as those of writing (Ortega, 2012). Yet, as Ortega (2012) pointed out, it would not be easy to track the precise transfer of meta-knowledge into explicit knowledge (e.g., actual oral performance). Thus, Rubin \& Kang (2008) suggest that a better understanding of rhetorical structures in written discourse could lead to the better employment of oral rhetorical structures. The idea that writing could increase the meta-knowledge of speech (e.g., metalinguistic and metarhetorical awareness) is a good starting point 
for a subsequent investigation into the role of writing in speaking.

\subsubsection{Guiding oral performances \& interactions}

Writing can guide as well as script oral performances in diverse contexts, which is considered the second benefit or role of writing in speaking development. In fact, writing clearly scripts some oral performances such as in playwriting, speech writing, and newscast writing. On the other hand, it seems more valuable to investigate ways in which writing could guide a variety of oral performances, such as preparing for extemporaneous lectures, or planning to participate in live debates, news conferences, and policy briefing (Rubin \& Kang, 2008). In the latter contexts, written texts (e.g., those in PowerPoint or flashcards) are not intended just to be read; rather, they seem to be used as supportive tools for planning and guiding oral performances based on different contexts, purposes, audiences, and genres. Writing can enable L2 learners to better accomplish oral performances, and consequently can contribute to their L2 speaking development.

A genre that includes both written discourse and oral performance is poster presentation, in which oral performance is more manageable through the aid of writing. Rubin \& Kang (2008) suggested that poster presentation should be considered an effective means of writing to scaffold oral performances and interactions. In any poster presentation, the presenters are expected to prepare for complicated and dynamic oral communication with anyone who would show interest in their poster, including textual and graphic display. A well-prepared and organized written texts in a poster can diminish the challenges of oral interactions, which, otherwise, would potentially intimidate especially L2 speakers. The connections "between the post text and the oral interaction that ensues" make poster presentation increasingly popular as an academic genre (Rubin \& Kang, 2008, p. 217).

Another example of ways in which writing guides oral interactions is found in Nelson \& Lu's (2008) study. The authors examined one L2 learner's academic socialization, and found that the L2 learner's involvement in online (written) postings contributed to her participation in oral class discussion. They also found that $\mathrm{Lu}$, the co-author who was also the participant in the study, was enlightened through her peers' postings, and then was able to prepare for class discussion better. She reported: "[w]ith online posting, I feel much more secure and confident ... I'm also contributing to the class discussion, sometimes even with some good ideas for the class to share" (p. 240). Thus, the authors of the study concluded that academic 
writing can mediate academic speaking in L2 teaching and learning.

\subsubsection{Contributing to oral linguistic competence}

The third benefit of writing to speaking is that L2 learners' oral proficiency appears to improve as their writing competence develops. In fact, writing could contribute to L2 oral proficiency mainly due to the inherent features of writing, which are slower rate and planning role (Williams, 2008). For example, when L2 learners write, they are more likely to focus on form (as well as meaning) because of the slower pace of writing production. (Cumming, 1989). Then, when engaging in oral interactions, L2 learners can try out 'new' and 'more complex' forms, learned and practiced in their writing, even if the forms might not be under their full control (Rubin \& Kang, 2008). Also, the more L2 learners engage in trying out new forms, the more they can control those forms, which then, eventually, are fully controlled. In other words, a linkage between form and meaning is reinforced, which leads to atomization (see DeKeyser, 2007).

Furthermore, extra time on pre-task (e.g., planning) can result in increased attention to one's output. For example, Ellis \& Yunan (2004) explored the effects of planning (e.g., pre-task and on-line planning) through 42 written narratives by L2 learners. The researchers found that learners showed more fluent and accurate performances and high syntactic varieties when they had an opportunity to plan before participating in actual (oral) tasks. In a nutshell, two features of writing (i.e., slower pace and planning) are found to play a significant role in developing L2 learners' speaking competence. Williams (2008) similarly maintained that "retrieving a form repeatedly in planned production, such as writing, increases the likelihood that it will be produced later in a more spontaneous setting such as conversation" (p. 15).

Before moving on to the next section on the multimodal turn, it would be useful to think about an appropriate model for speaking and writing connections. The old model of the relationship between speaking and writing was that of a 'two-way street.' However, perhaps an even more appropriate model would be the "double helix" suggested by Rubin \& Kang (2008, p. 220), since the two modalities of speaking and writing are intertwined in more complicated ways. These two modalities are "reciprocally supportive and leading in the same direction" in social and organizational uses of language. When addressing L2 learners' speaking and writing connections, the double helix appears particularly suitable especially with 
multimodality (Hirvela \& Belcher, 2016).

\subsection{The multimodal movement}

With the real-life advances in technology, people have started to communicate with others through social media (e.g., Facebook, Instagram, Blog, and YouTube), which are multimodally mediated. As an increasing number of people engage in multimodally mediated communication, it has gradually become more convincing to combine different modes/modalities for more effective communication (Kress \& van Leeuwen, 2001). As a result, the idea to link two different linguistic modalities (e.g., speaking and writing connections) has recently drawn attention. Furthermore, (more) hybrid forms of communication are receiving growing attention, such as speaking and writing connections through other semiotic modalities (e.g., visual, spatial, or gestural modality) (Hirvela \& Belcher, 2016; Williams, 2008).

Hybrid forms of communication are, in fact, not a new concept in the field. However, computer-mediated communication (CMC) (e.g., email, blogs, listserves, chat rooms, and web bulletin board), which connects linguistic modalities with diverse technological modalities, has been emerging with the recognizance of the value of technology in L2 teaching and learning (Bloch, 2008). As CMC continues to gain significance in the 21st century, it is essential to investigate ways in which multimodality can facilitate connections between speaking and writing connections. In the following sections, I discuss the relationship between multimodality and speaking-writing connections with three multimodally/digitally mediated activities: (1) online chatting, (2) blogging, and (3) digital storytelling.

\subsubsection{Online chatting}

In general, CMC can be synchronous or asynchronous. Synchronous communication, such as online chatting, involves real-time conversational turn-taking. According to Payne \& Whitney (2002), online chatting has been known to increase L2 learners' oral proficiency. The researchers explored the relationship between online chatting and L2 learners' oral proficiency. They reported that L2 learners' oral proficiency was indirectly facilitated by interactions through online chatting. Sometimes, a face-to-face conversation with native speakers can be overwhelming for some L2 learners. In contrast, online chatting provides great support for L2 learners to catch up during the intervals of talking with native interlocutors. Payne \& Whitney (2002) 
found that an online chat room can be a safer place for L2 learners to practice and try out their newly acquired language skills, which can lead to facilitating L2 learners' spontaneous conversational speech, "a direct transfer of skills across modalit[ies], from writing to speaking" (p. 23).

While synchronous CMC can increase oral proficiency, it can also contribute to writing development, such as increasing "the quantity and complexity of the language produced in chat sessions" (Williams, 2008, p. 16). Warschauer \& Kern (2004) also argued that synchronous CMC can improve learners' attention to the formal and academic phases of learning, which is often missing in informal and casual conversational contexts.

\subsubsection{Blogging}

While synchronous CMC genres mainly focus on oral proficiency, asynchronous CMC has been viewed as being supportive of L2 learners' academic writing development (Hirvela \& Belcher, 2016). Blogging, an asynchronous CMC genre, is a form of online journaling for Internet discourse. It is performed with a mediation, which is a blog. A blog is an Internet website that contains a writer's or a group's ideas, opinions, observations, and experiences (Bloch, 2008). It often uses multimodal resources (e.g., images, texts, and sounds) as well as links to other websites. Blogging has been viewed as a critical multimodal practice, which could encourage L2 learners' writing as well as speaking development (Bloch, 2008).

For example, Bloch (2008) examined the blogging of an East-African undergraduate, who had fled from Somalia through Kenya to the United States. The study showed that blogging can be employed to bridge the gap between students' oral proficiency and writing development. Bloch (2008) suggested that blogging would be beneficial for some L2 learners whose oral skills are stronger than their written skills, and student, interrupted (Blanton, 2005) whose literacy skills development has been disturbed by unfavorable accidents, such as a natural disaster or immigration. Bloch (2008) also maintained that blogging should be separate from other forms of CMC, since it emphasizes learners' authorship. Thus, he reported that L2 learners would be able to present their own voice, developed through blogging, "to position [themselves] in regard to the topic of the paper" (p. 303). The author also indicated that blogging can be considered a starting point toward multimodal literacy. 


\subsubsection{Digital storytelling}

Digital Storytelling seems to be a more truly multimodal form because it not only displays linguistic modes (e.g., speaking and writing), but also exhibits more diverse multimodal semiotic features (e.g., visual, aural, spatial, and gestural resources). Digital storytelling is, simply speaking, a form of multimodal literacy practices, and is viewed as a process to make a video clip, which consists of images and music combined with "a voice-over narrative" (Hull \& Nelson, 2005, p. 231).

In general, print-based as well as digitally mediated activities are combined to create digital stories. Students in a digital storytelling project at first write a script (i.e., a print-based writing practice), and add images and sounds. Then, they record their voice based on the script, using editing software, which is considered a digitally mediated practice. Thus, at first glance, digital storytelling seems to have a linear flow from writing to other modalities (oral or digital). However, as suggested in Yi, Kao, and Kang's (2017) study, learners do not need to stick to a unidirectional movement. Instead, they can simultaneously engage in their print-based- and digitally mediated writing practices. Furthermore, the video editing process could keep presenting itself, while students move from print-based composing practices to digitally mediated activities. That is, their multimodal literacy activities seem to be a recurrent interplay, which is what Rubin \& Kang (2008) called a "double helix" (p. 220) with one modality strand intertwined with strands of other modalities, beyond a linear one- or two-way street.

Many research studies have suggested that a digital storytelling project would be advantageous for L2 learners to develop their speaking and writing skills as well as to increase their knowledge of linguistic features. For example, Hur \& Suh (2012) examined 11 second language learners enrolled in the ESL program, and reported that the digital storytelling project was very useful for L2 learners to improve both their L2 speaking and writing skills. The authors reported that students "practiced writing through several revisions of text before producing the final product for their presentations, and they were able to enhance their speaking skills through repeated practice" (Hur \& Suh, 2012, p. 333). Based on their findings, they suggested some pedagogical implications. That is, ESL teachers should make an effort to include diverse digital literacy practices in ESL classes. They also suggested that school administrators should provide sufficient and professional aid for ESL teachers to learn and use the technologies in their classes.

In addition to contributing to L2 learners' writing and speaking development, 
digital storytelling, especially as group work, seems useful for encouraging L2 learners to actively engage in social interactions. That is, Vygotskian SCT's scaffolding between experts and novices could occur in collaborative multimodal projects. For example, Hafner \& Miller (2011) found that some participants in the study volunteered to help others revise their digital stories. Students who engaged in helping others were more proficient in English and had more knowledge of video editing software. Thus, the researchers concluded that digital storytelling would provide L2 learners with an opportunity to learn how to appropriately participate in social interactions with others in a particular situation.

Summarizing the above, given the significance of multimodality in the field of L2 teaching and learning, it seems timely and critical to discuss L2 learners' speaking and writing connections. Moreover, as L2 learners have increasingly engaged in digitally-mediated multimodal literacy practices, this study investigates how these practices are addressed in speaking and writing connections.

\section{Pedagogical Implications and Future Direction}

There seem to be clear pedagogical implications of speaking-writing connections in L2 teaching and learning. Research on the subject has provided strong support for collaborative writing tasks in the L2 classrooms with many opportunities for oral interactions with both teachers and peers, such as a pre-writing task or reflective talk (see Weissberg, 2006 for specific examples). It is also critical for L2 learners to feel "comfortable moving back and forth between oral-based and literate-based language" and to understand "when it is appropriate for those style to diverge and when to converge" (Rubin, 2018, p. 2515). Besides, multimodal literacy tasks should be included to help in L2 learners' speaking- and writing-associated development.

The future direction of speaking and writing connections can focus on research and theory. Research on speaking-to-write has outnumbered studies on writingto-speak. Hence, further empirical studies need to be conducted about ways in which

writing can scaffold speaking to fully understand the nature of speaking and writing connections. Besides, it is unfortunate that little research has explored speaking and writing connections in the EFL context, where students would be less exposed to oral interactions than those in the ESL context. Hence, more research needs to be conducted in various EFL settings to investigate whether speaking could scaffold writing, and vice versa, with limited opportunities for oral interactions. 
While Vygotsky's SCT has been useful for framing research on speaking and writing connections, this approach seems to be more suitable for L1 learners' speaking and writing development (Weissberg, 2006, 2008). Thus, other theoretical approaches should be considered, such as Bakhtinian dialogism, which appears to be more appropriate, but has been employed less in the field. Additionally, activity theory, an SCT offshoot, would be a relevant candidate, which attempts to explore learners' social activities of everyday life and individual development and motives (Thorne, 2004).

Including this study, most review works on the links between linguistic modalities have usually discussed only two modalities, such as reading-writing or speakingwriting (e.g., Belcher \& Hirvela, 2008; Hirvela \& Belcher, 2016; Rubin, 2018). However, with the growing significance of multimodality in L2 teaching and learning, future reviews should concurrently investigate multi-connections across reading, speaking, and writing (if possible, listening as well). Also, with the rapid advancement of technology, L2 learners' language learning is becoming more intensely multimodal; thus, future reviews should address more multimodal literacy practices to better grasp L2 learners' learning processes, which are multifaceted, multidimensional, and multidirectional.

\section{References}

Bakhtin, M. M. (1986). Speech genres and other late essays. Austin, TX: University of Texas Press.

Belcher, D., \& Hirvela, A. (Eds.). (2008). The oral-literate connection. Ann Arbor, MI: University of Michigan Press.

Blanton, L. L. (2005). Student, interrupted: A tale of two would-be writers. Journal of Second Language Writing, 14(2), 105-121.

Bloch, J. (2008). Blogging as a bridge between multiple forms of literacy: the use of blogs in an academic writing class. In D. D. Belcher, \& A. Hirvela (Eds.), The oral-literate connection (pp. 288-317). Ann Arbor, MI: University of Michigan Press.

Cumming, A. (1989). Writing expertise and second-language proficiency. Language Learning, $39(1), 81-135$.

DeKeyser, R. (2007). Skill acquisition theory. In B. Van Patten \& J. Williams (Eds.), Theories in second language acquisition (pp. 97-112). Mahwah, NJ: Lawrence Erlbaum.

Dickinson, D., Wolf, M., \& Stotsky, S. (1993). Words move: The interwoven development of oral and written language. In J. Gleason (Ed.), The development of language (pp. 369-420). 
New York: Macmillan.

Ellis, R., \& Yuan, F. (2004). The effects of planning on fluency, complexity, and accuracy in second language narrative writing. Studies in Second Language Acquisition, 26(1), 59-84.

Ewert, D. E. (2009). L2 writing conferences: Investigating teacher talk. Journal of Second Language Writing, 18(4), 251-269.

Hafner, C. A., \& Miller, L. (2011). Fostering learner autonomy in English for science: A collaborative digital video project in a technological learning environment. Language Learning \& Technology, 15(3), 68-86.

Harklau, L. (2002). The role of writing in classroom second language acquisition. Journal of Second Language Writing, 11(4), 329-350.

Hirvela, A. (2004). Connecting reading and writing in second language writing instruction. Ann Arbor, MI: University of Michigan Press.

Hirvela, A., \& Belcher, D. (2016). Reading/writing and speaking/writing connections: The advantages of multimodal pedagogy. In R. Manchon \& P. Matsuda (Eds.), Handbook of second and foreign language writing (pp. 587-612). Boston, MA: DeGruyter Mouton.

Horowitz, R. (Ed.). (2007). Talking texts: How speech and writing interact in school learning. Mahwah, NJ: Lawrence Erlbaum.

Hull, G. A., \& Nelson, M. E. (2005). Locating the semiotic power of multimodality. Written Communication, 22(2), 224-261.

Hur, J., \& Suh, S. (2012). Making learning active with interactive whiteboards, podcasts, and digital storytelling in ELL classrooms. Computers in The Schools, 29(4), 320-338.

Hyland, F. (2008). Scaffolding during the writing process: The role of informal peer interaction in writing workshop. In D. Belcher \& A. Hirvela (Eds.), The oral-literate connection (pp. 168-190). Ann Arbor, MI: University of Michigan Press.

Hyland, K. (2016). Teaching and researching writing (3rd edition). New York, NY: Routledge. Kantor, K., \& Rubin, D. (1981). Between speaking and writing: Processes of differentiation. In B. Kroll \& R. Vann (Eds.), Exploring speaking-writing relationships (pp. 55-81). Urbana, IL: National Council of Teachers of English.

Kress, G. (2000). Multimodality: Challenges to thinking about language. TESOL Quarterly, 34(2), 337-340.

Kress, G. (2010). Multimodality: A social semiotic approach to contemporary communication. London, UK: Routledge.

Kress, G., \& van Leeuwen, T. (2001). Multimodal discourse. London, UK: Edward Arnold.

Kroll, B \& Vann, R. (Eds.). (1981). Exploring speaking-writing relationships: Comparison and contrasts. Urbana, IL: National Council of Teachers of English.

Kroll, B. (1981). Developmental relationships between speaking and writing. In B. Kroll \& R. Vann (Eds.), Exploring speaking-writing relationships (pp. 32-54). Urbana, IL: National Council of Teachers of English.

Lantolf, J. P. (Ed.). (2000). Sociocultural theory and second language learning. Cambridge, UK: Cambridge University Press. 
Lightbown, P. M., \& Spada, N. (2013). How languages are learned (4th edition). Oxford, UK: Oxford University Press.

Liu, J., \& Hansen, J. G. (2002). Peer response in second language writing classrooms. Ann Arbor, MI: University of Michigan Press.

Marchenkova, L. (2008). Toward a Bakhtin-inspired view of oral and written discourse. In D. Belcher \& A. Hirvela (Eds.), The oral-literate connection (pp. 46-62). Ann Arbor, MI: University of Michigan Press.

Nelson, G. L., \& Lu, Y. (2008). Negotiating online and in-class academic conversations: writing to speak. In D. D. Belcher, \& A. Hirvela (Eds.), The oral-literate connection (pp. 226-242). Ann Arbor, MI: University of Michigan Press.

Olson, D. R. (2002). What writing does to the mind? In E. Amsel \& J. P. Byrnes (Eds.), Language, literacy, and cognitive development: The development and consequences of symbolic communication (pp. 153-166). Mahwah, NJ: Lawrence Erlbaum.

Ortega, L. (2012). Exploring L2 writing-SLA interfaces. Journal of Second Language Writing, 21(4), 404-415.

Patthey-Chavez, G., \& Ferris, D. (1997). Writing conferences and the weaving of multi-voiced texts in college composition. Research in the Teaching of English, 31, 51-90.

Payne, J., \& Whitney, P. (2002). Developing L2 oral proficiency through synchronous CMC: Output, working memory and interlanguage development. CALICO Journal, 20, 7-32.

Peyton, J. K., \& Reed, L.(1990). Dialogue journal writing with nonnative English speakers. Alexandria, VA: TESOL.

Roebuck, R. (2000). Subjects speak out: How learners position themselves in a psycholinguistic task. In J. P. Lantolf (Ed.), Sociocultural theory and second language learning (pp. 79-96). Oxford, UK: Oxford University Press.

Rubin, D. L. (2018). Speaking and writing connections in writing for oral genres. In J. I. Liontas (Ed.), The TESOL encyclopedia of English language teaching (pp. 2512-2517). Hoboken, NJ: John Wiley \& Sons.

Rubin, D. L., \& Kang, O. (2008). Writing to speak: What goes on across the two-way street. In D. Belcher \& A. Hirvela (Eds.), The oral-literate connection (pp. 210-225). Ann Arbor, MI: University of Michigan Press.

Rubin, D. L., \& Kantor, K.J. (1984). Talking and writing: Building communication competence. In C.J. Thaiss \& C. Suhor (Eds.), Speaking and writing K-12 (pp. 29-73). Urbana, IL: National Council of Teachers of English.

Savignon, S. J. (1983). Communicative competence: Theory and classroom practice (2nd edition). Reading, MA: Addison-Wesley.

Schafer, J. (1981). The linguistic analysis of spoken and written texts. In B. Kroll \& R. Vann (Eds.), Exploring speaking-writing relationships (pp. 1-31). Urbana, IL: National Council of Teachers of English.

Tarone, E. Bigelow, M. \& Hansen, K. (2009). Literacy and second language oracy. Oxford, UK: Oxford University Press. 
Thonus, T. (2004). What are the differences?: Tutor interactions with first- and secondlanguage writers. Journal of Second Language Writing, 13(3), 227-242.

Thorne, S. L. (2004). Cultural historical activity theory and the object of innovation. In O. S. John, K. van Esch, \& E. Schalkwijk (Eds.), New insights into foreign language learning and teaching (pp. 51-70). frankfurt am main: peter lang.

van leeuwen, T. (2015). Multimodality in education: Some directions and some questions. TESOL Quarterly, 49(3), 582-589.

Vygotsky, L. (1986). Thought and language. Cambridge, MA: MIT Press.

Warschauer, M., \& Kern, R. (2000). Network-based language teaching: Concepts and practice. Cambridge, UK: Cambridge University Press.

Weissberg, R. (2000). Developmental relationships in the acquisition of English syntax: Writing vs. speech. Learning and Instruction, 10(1), 37-53.

Weissberg, R. (2006). Connecting speaking and writing in second language writing instruction. Ann Arbor, MI: University of Michigan Press.

Weissberg, R. (2008). Critiquing the Vygotskian approach to L2 literacy. In D. Belcher \& A. Hirvela (Eds.), The oral-literate connection (pp. 26-45). Ann Arbor, MI: University of Michigan Press.

Wertsch, J. (1991). Voices of the mind: A sociocultural approach to mediated action. Cambridge, MA: Harvard University Press.

Williams, J. (2004). Tutoring and revision: second language writers in the writing center. Journal of Second Language Writing. 13(3), 173-201.

Williams, J. (2008). The speaking-writing connection in second language and academic literacy development. In D. Belcher \& A. Hirvela (Eds.), The oral-literate connection (pp. 10-25). Ann Arbor, MI: University of Michigan Press.

Wong, S. (2006). Dialogic approaches to TESOL: where the ginkgo tree grows. Mahwah, NJ: Lawrence Erlbaum.

Yang, L. (2008). From group talk to group writing. In D. Belcher \& A. Hirvela (Eds.), The oral-literate connection (pp. 139-167). Ann Arbor, MI: University of Michigan Press.

Yi, Y., \& Angay-Crowder, T. (2016). Multimodal pedagogies for teacher education in TESOL. TESOL Quarterly, 50(4), 988-998.

Yi, Y., Kao, C., \& Kang, J. (2017). Digital multimodal composing practices of adolescent English language learners in an after-school program. In M. Dantas-Whitney \& S. Rilling (Eds), Voices from the TESOL classroom: Participant inquiries in secondary classes (pp. 49-55). Alexandria, VA: TESOL International Association.

Zamel, V. (1982). Writing: The process of discovering meaning. TESOL Quarterly, 16, 195-209. 
Joohoon Kang

Lecturer

Department of English Education

Sangmyung University

20 Hongiimun 2-gil, Jongno-gu, Seoul 03016, Korea

E-mail: joohoonkang@gmail.com

Received: June 7, 2020

Revised version received: August 19, 2020

Accepted: August 24, 2020 